fundamentally new areas of investigation, with the exception of the effects of different schedules of reinforcement: even this work led less to the discovery of new principles than to the elaboration of his basic postulate of reinforcement. If a rat is not rewarded for pressing a bar until one minute has elapsed since the last reward, it learns to press infrequently for a time after reward is delivered and more frequently towards the end of the one minute interval. Skinner explained this result by pointing out that only bar presses made after one minute has elapsed will be reinforced, and hence the animal will come to give more responses after that interval and fewer immediately after reward; the nature of the timing processes that underlie such behaviour was of no interest to him.

Within the limits that Skinner imposed on his own thinking, he often displayed considerable ingenuity. He was amongst the first to distinguish clearly between the classically conditioned Pavlovian reflex and 'operant' responses in which reward is made contingent on the occurrence of the response. He also showed great skill in the design of apparatus for the automatic recording of behaviour, though at the expense of restricting the behaviour recorded. He does not make it altogether clear whether the famous Skinner box was an attempt to make the recording of behaviour more objective or whether it was a device to enable him to carry out more experiments with less effort.

It is interesting to speculate how Skinner's impoverished view of the task of psychology came to attract so wide a following. His insistence on quantitative results may have appealed to those who wanted psychology to attain the respectability of a science; his doctrine of the malleability of man fitted the prevailing ethos of self-improvement in America; his insistence that what was inside the organism was the province of physiology, whereas psychology should concentrate on the whole organism gave psychology status as an independent discipline; and his concentration on the role of reinforcement to the exclusion of all other problems obviated the difficulty of thinking about such complicated questions as how the organism stores or retrieves information.

Psychology is now a very different subject and the study of mental processes is once more fashionable. The next volume of Professor Skinner's autobiography will doubtless record how his fame amongst the general populace spread at the time his influence on the academic community was waning. One can only hope that he will relax his professional austerity sufficiently to tell us not only what happened but how he felt about it.

Stuart Sutherland is Professor of Experimental Psychology at the University of Sussex, Brighton, UK.

\section{The Cardinal Sin}

\begin{tabular}{l} 
Ann M. Clarke \\
A. D. B. Clarke \\
\hline
\end{tabular}

Cyril Burt: Psychologist. By L. S. Hearnshaw. Pp. 370. (Hodder and Stoughton: London; Cornell University Press: Ithaca, New York, 1979.) $£ 8.95$.

THIS is a book about an eminent psychologist who committed the scientist's cardinal sin, deception and fraud, during a long productive life which brought him nearly all possible distinctions except Fellowship of the Royal Society. $\mathrm{He}$ is to be condemned not for the views he espoused, many of which we share albeit in a less extreme form, but for his irregular conduct over many years. On the penultimate page of Sir Cyril Burt's biography the author writes:

"It would be totally unfair for a final judgement on Burt to focus on his deceptions to the exclusion of all his positive achievements. He was not, perhaps, either by training or temperament a scientist. He was too impatient to reach, and too confident of having reached, firm conclusions which became for him very early in his career. articles of almost religious faith to be defended at all costs. Yet he brought to psychology many conspicuous gifts..."

Be that as it may, his major claim to fame certainly outside his profession, was his work on the heritability of intelligance, and in this connection many distinguished scientists on both sides of the Atlantic accepted his findings on the assumption that the data as reported were sound.

This beautifully written and well researched book records the life and works of an often charming, sometimes generous and kind, always erudite yet unscrupulous man who deserves a high place in science's rogues' gallery. In 1905, while reading classics at Oxford, he recorded in his diary "My purpose in life concerns primarily myself. It is to produce one perfect being for the universe", and went on to list the necessary virtues. Regrettably he failed to follow his own precepts. Shortly after graduation he was appointed assistant to Charles Sherrington at Liverpool. He remained there five years, commencing his research career and gathering his first data to prove that what he called "general cognitive ability" was innate. As Professor Hearnshaw notes:

"inadequate reporting and incautious conclusions mark this first incursion of Burt into the genetic field. We have here right at the beginning of his career, the seeds of later troubles."

In 1912, with a reputation already firmly established and on the recommendation of Spearman and Sherrington, Burt was appointed psychologist to the London County Council on a half-time basis. Spearman had written:

"I can add that he is considered by most experts to be the most brilliant and promising of the younger generation of psychologists in the British Isles..."

Burt seems to have worked indefatigably to collect data on abilities and attainments of London school children and on the development of mental and scholastic tests for their assessment.

Appointed in 1922 to a half-time post in the National Institute of Industrial Psychology to organise its vocational department, Burt remained there for two years and among other things taught some of his colleagues to 'estimate' the IQs of adults without actually testing them! In 1924 he was elected to a part-time Professorship of Educational Psychology in the then London Day Training College, later to become the Institute of Education.

In 1931, aged 48, Burt succeeded Charles Spearman in the Chair of Psychology at University College, London. During the next thirty years, factor analysis became his major interest. He began to make claims to priority as first user of this method, but these were at once retracted when Spearman challenged him. With the latter's death in 1945 , however, Burt began to rewrite the history of these statistical techniques, dethroning Spearman as their originator. In a number of publications, especially from 1947 onwards, he began "to make claims about his own early work which were demonstrably contrary to the truth" (page 173). Far from having followed Spearman's lead, he now alleged that he had pursued a different route, and that he was in disagreement with Spearman from the start, a view belied by extant correspondence between them. Later "the claims got more and more extravagant". As Hearnshaw notes, there is a pathology here, of which we could ourselves offer further examples.

Burt retired from his Chair at University College in 1950, after unsuccessfully trying to influence the appointment of his successor. His subsequent attempts at interfering with the running of the Department ultimately led to his exclusion from the College on the decision of the Provost who had earlier warned the new incumbent against allowing Burt any access. The twenty-one years of retirement witnessed a surge of publications on a major theme, the importance of genetic factors in human ability and the unimportance of environment. His most influential papers were all published in journals with which he had a close personal connection. As founder and editor of The British Journal of Statistical Psychology from 1947 to 1963 and later as assistant editor, he used it as a frequent outlet. His gross abuse of editorial powers was to some extent known at the time, at least to people like 
ourselves around London. Apart from publishing 63 articles under his own name, he frequently altered authors' texts without permission, often misrepresenting their intention and adding favourable references to his own work. In addition " Of the more than forty 'persons' who contributed reviews, notes and letters... well over half are unidentifiable, and judging from the style and content were pseudonyms for Burt' (page 245).

Burt could also be kind and generous, as he usually was to us; Hearnshaw records many tributes from former colleagues and students. He could equally be autocratic and vicious towards, for example, a close colleague to whom he wrote a barrage of memoranda and letters pouring scorn on his research. All this to someone to whom staff and students were deeply attached, and upon whose devoted labours the functioning of the Department largely depended (page 143).

With his undoubtedly brilliant mind and wide educational and clinical experience, Burt became from the 1920 s and onwards much in demand for evidence and advice on a variety of practical problems. Hearnshaw suggests that he influenced the developing pattern of English education, as well as contributing to policy in such fields as mental deficiency, delinquency and War Office selection procedures.

So far as any scientific theory is concerned it matters little whether Burt's claim to possess a vast store of data on the intellectual status of relatives was true; their poor quality and many anomalies in reporting were outlined in three independent publications in 1974. However, when in 1976 Dr Gillie of The Sunday Times, with our support, charged Burt with fraud there were strong protests. Such charges, particularly in connection with his sample of monozygotic twins reared apart (unique both in size and in extent of environmental differences, mainly reported in the $1950 \mathrm{~s}$ and $60 \mathrm{~s}$ ) could, however, be made with impunity once Dr Gillie's fairly extensive enquiries had established that Burt's alleged collaborators, Margaret Howard and J. Conway, existed in no relevant records, nor were they known to colleagues at University College nor to his secretary/housekeeper. Space precludes a detailed account of Hearnshaw's later careful researches in connection with the charges; in his endeavour to be both brief and balanced, he has omitted many of Burt's conflicting stories to interested scholars during the last few years of his life, confining himself to a small but adequate sample.

Hearnshaw presents overwhelming evidence

"that neither Burt nor any of his alleged assistants carried out any field work after 1955 , and it is probable that all his data, such as it was, had been collected prior to his retirement in 1950, most of it, indeed, prior to the Second World War. Burt certainly added no data himself after leaving University College, and there is no evidence of any contact or communication with any assistants" (page 239).

Moreover, he did not have, as he frequently alleged, material stored there.

The biographer acknowledges the possibility that the data simply did not exist, but writes:

"Assuming that the data were collected in the first instance, and there seems reasonable grounds for thinking that at least some was, what happened to it? The answer almost certainly, is that the bulk of it was destroyed during the war."

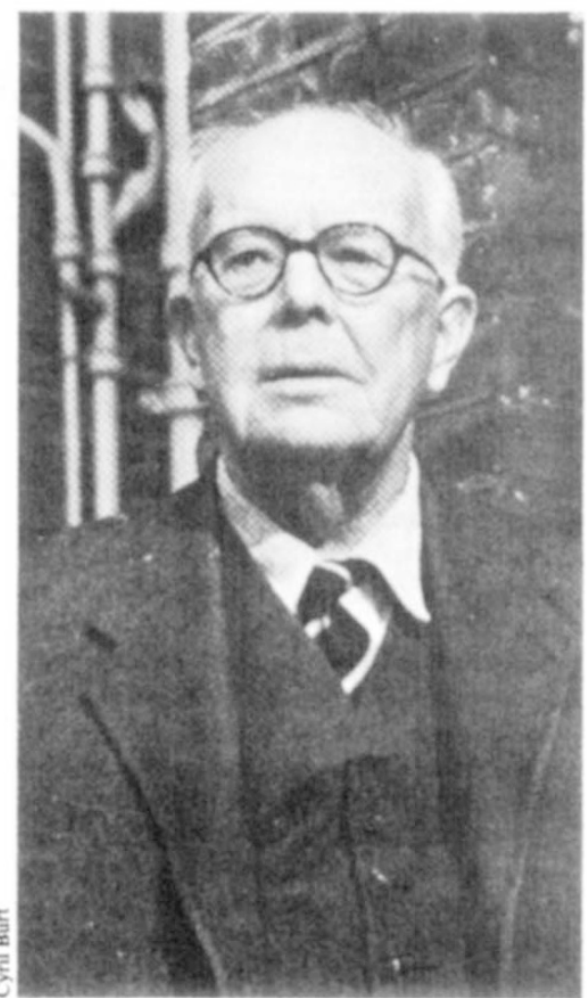

The evidence in support of this conclusion is less than convincing, and includes a letter from Burt to University College written from Aberystwyth in February 1941 , requesting permission to store

"files of case-histories of defective, neurotic and delinquent children, rather large collections of children's drawings, compositions etc. systematically gathered while I still had access to London schools...' (page 248).

There is no mention of twin data nor any other material relating to intelligence test results for relatives. Whatever the truth of the matter, one thing is certain: as we pointed out over two years ago, the unknown Miss Conway did not double the size of the separated monozygotic twin sample, between 1955 and 1958, as 'she' and Burt claimed, nor were any further cases examined thereafter. Furthermore, it seems safe to assume that whatever data Burt may once have collected on various kinship correlations these, as M. McAskie (Hull) and more recently D. Dorfman (Iowa) have contended, were not available to him at the time of writing his seminal papers.

It is also clearly established that information on declining educational standards said to have been compiled by another unknown lady, Miss M. G. O'Connor, which included surveys carried out in 1955 and 1965 (discussed in the 1969 Black Paper and in the Irish Journal of Education) "were at least in part fabricated" (page 259).

Hearnshaw takes issue with those who like ourselves would dismiss Burt altogether on this evidence, pointing to the esteem with which he was held almost universally in the early stages of his career, and by many up to the time of his death. Among these were two of our former teachers, who we believe would never have expressed their approval had they known what is revealed in this book. The author alludes to Burt's use of short cuts, yet maintains that his contribution to applied psychology was important and must be taken into account in the final evaluation. We have reservations about this conclusion. For example, we have a little known report, published in 1924, in which he states that by means chiefly of psychological and educational tests, he had made an intensive study of backward children. "During the four weeks covered by my visit to Birmingham I personally tested 562 children. This was at an average rate of rather over ten minutes to every child". The psychological examination which he personally undertook used "chiefly the Binet-Simon tests of intelligence revised for English children". From our own extensive experience of testing such children we find this a disturbing example of taking short cuts, particularly as Burt was subsequently regarded as an authority on The Subnormal Mind. Later advances in this applied field in fact owed virtually nothing to him.

We cannot recommend too strongly this scholarly yet easily read biography. For this reason we refrain from comment on the well researched and fascinating suggestions concerning Burt's pathological personality and why he behaved as he did. This must have been a difficult book to write, partly because Burt was in Professor Cohen's words "a polymath of Renaissance dimensions"; partly because it was originally commissioned by Burt's sister who, aftet the public charges made against her brother, remained "convinced of Cyril's integrity"; and partly because of the heavy responsibility for sifting the evidence and arriving at an acceptable account of the life and works of ar eminent psychologist who inspirec devotion in some and distrust in others.

Two disturbing questions remain. First, why were Burt's deceptions unrecognised for so long? Second, is this case unique in our time?

Ann M. Clarke is Reader in Educational Psychology in the Department of Educational Studies, and A. D. B. Clarke is Professor of Psychology at the University of Hull, UK. 